BMJ Open Diabetes Research \& Care

\section{Service user and community clinician design of a partially virtual diabetic service improves access to care and education and reduces amputation incidence}

To cite: Watt A, Beacham $A$ Palmer-Mann L, et al. Service user and community clinician design of a partially virtual diabetic service improves access to care and education and reduces amputation incidence. BMJ Open Diab Res Care 2021;9:e001657. doi:10.1136/ bmjdrc-2020-001657

- Supplemental material is published online only. To view please visit the journal online (http://dx.doi.org/10.1136/ bmjdrc-2020-001657).

AIW deceased since 13th December 2017.

Received 9 June 2020 Revised 12 November 2020 Accepted 25 November 2020

Check for updates

(C) Author(s) (or their employer(s)) 2021. Re-use permitted under CC BY-NC. No commercial re-use. See rights and permissions. Published by BMJ.

For numbered affiliations see end of article.

Correspondence to Dr Richard Paisey; richard.paisey@nhs.net

\section{ABSTRACT}

Introduction Design of an integrated diabetes service based on needs of service users (persons living with diabetes) and community clinicians in a semirural lowincome health district of the UK.

Research design and methods One hundred and eighty-five service users engaged through public meetings, questionnaires and focus groups. General practice staff contributed views through workshops and questionnaires. Analysis of feedback indicated service user needs for better access to education, dietary advice and foot care. General practice staff endorsed these views and requested regular access to secondary care in the community. Seven hundred persons registered with diabetes attended eight well-being events in the community. From 2017 virtual practice multidisciplinary patient reviews, virtual referral of foot cases and nonface-to-face helplines were developed. A National Health Service (NHS) approved 'App' and web-based personalized education support for those recently diagnosed with diabetes was introduced.

Results Engagement in education for those recently diagnosed with diabetes increased from $5 \%$ to $71 \%$. Weight and hemoglobin $\mathrm{A} 1 \mathrm{c}(\mathrm{HbA} 1 \mathrm{c})$ levels before and 6 months after starting the program were $99.4 \pm 25$ and $95.5 \pm 24.2 \mathrm{~kg}$ and $59.3 \pm 16$ and $54.8 \pm 12.9 \mathrm{mmol} / \mathrm{mol}$, respectively, $p=0.00003$ and 0.003 . Of those engaging at well-being events, 44 had missed regular follow-up. One hundred and seventy-five cases were reviewed virtually with practice staff by the secondary care team avoiding referral to the hospital diabetic clinic. One hundred and seventy-six referrals were made to the virtual multidisciplinary diabetic foot team clinic. Major amputation incidence declined from 13 to 3 major procedures/10 000 per annum and minor amputation from 26 to 18/10 000. Percentage bed day occupancy by persons with diabetes fell significantly in the district general hospital.

Conclusions Integrated community-based diabetes care delivery has been achieved with partially virtual reviews. Patient education, secondary care in the community, access to dietetic advice and foot care outcomes have all improved.

\section{Significance of this study}

What is already known about this subject?

- Quality outcome framework, education and multidisciplinary secondary care have improved services for diabetes in England. However, access to services remains difficult for many patients.

What are the new findings?

- Codesign of integrated diabetes care by service users has been shown to:

Improve access to education and dietary advice with improvement in weight and hemoglobin A1C. Reduce major and minor lower extremity amputation incidence sustained for 3 years.

Achieve improved outcomes with a partly virtual service.

How might these results change the focus of research or clinical practice?

- This study provides a model to enhance access to diabetes care and reduce foot complications. The virtual clinic aspects of the service can safely reduce direct contact between patient and clinician now advisable to reduce risk of COVID-19.

\section{INTRODUCTION}

Diabetes and its complications account for $10 \%$ of the total National Health Service (NHS) budget, and diabetes incidence is rising. ${ }^{1}$ The quality outcome framework (QOF) process, Public Health England cardiovascular disease profiles, National Diabetes Audit and National Diabetes Foot Audit have regularly and extensively audited diabetes care across England. ${ }^{2-4}$ National Institute for Health and Care Excellence (NICE) guidelines, National Service Framework documents and Diabetes UK have developed standards of diabetes care 
expected from NHS providers. ${ }^{5}{ }^{6}$ Three key targets to be monitored at annual review are hemoglobin Alc (HbA1c), serum lipids and blood pressure. These risk factors are powerful predictors of diabetic microvascular and macrovascular complications, ${ }^{78}$ which can best be addressed in general practice. In 2019, QOF for diabetes was revised to allow for frailty and rationalization of statin and blood pressure therapy and avoidance of harm from overtreatment. $^{9}$

It is now widely recognized that greater integration of diabetes services is essential in order to meet these needs, enhance access to diabetes care and improve QOF outcomes. ${ }^{10-12}$ Most importantly, the person living with diabetes should be helped to explore their own preferences for lifestyle change enhanced by lifestyle opportunities in their local area. ${ }^{13} 14$

The progression to more community-based care in the UK began with a randomized trial of delegation of diabetes care to general practice in Cardiff and reported in $1984 .{ }^{15}$ Attendance was poorer in general practice, and 5 -year outcomes including mortality were worse in the general practice care group. More recently, integration of diabetes secondary care with general practice has been more successful with definition of aspects of the service that still require management in secondary care: 'the super six model'. ${ }^{16}$ In 2005 in Newham, East London, the need for patient engagement in a multiethnic population was met by structured community delivery of care and enhancement of general practice competencies. ${ }^{17}$ From 2013, the WISDOM project has placed secondary care for diabetes almost entirely in the community. ${ }^{18}$ In Alaska, there has been an impressive success from complete reorganization of all health services based on service user ownership of the whole process. ${ }^{19}$ These innovations have highlighted the need for diabetes care to be integrated into communities with involvement of service users.

North Devon has a population of 166000 people and a slightly higher than the NHS England average incidence of diabetes at $7.5 \%$. However, variation exists as there are areas of affluence and pockets of high deprivation ${ }^{20}$ in association with stark inequalities in health outcomes. Seventeen general practices (community physicians and allied health professionals) provide services for a population spread over six main towns and an additional rural population spread over 419 square miles. Access to secondary care can be difficult because of limited public transport and a challenging minor road network.

A more integrated diabetes service was considered to be the most appropriate approach to improve access to care and outcomes. Sustainability and Transformation Programme (STP) funding provided the opportunity to initiate these changes. ${ }^{21}$ This work was inspired and begun by the late AIW, physician and diabetes consultant. This report describes the development and successful delivery of a partially virtual integrated diabetes care in North Devon based on needs expressed by service users and healthcare providers.

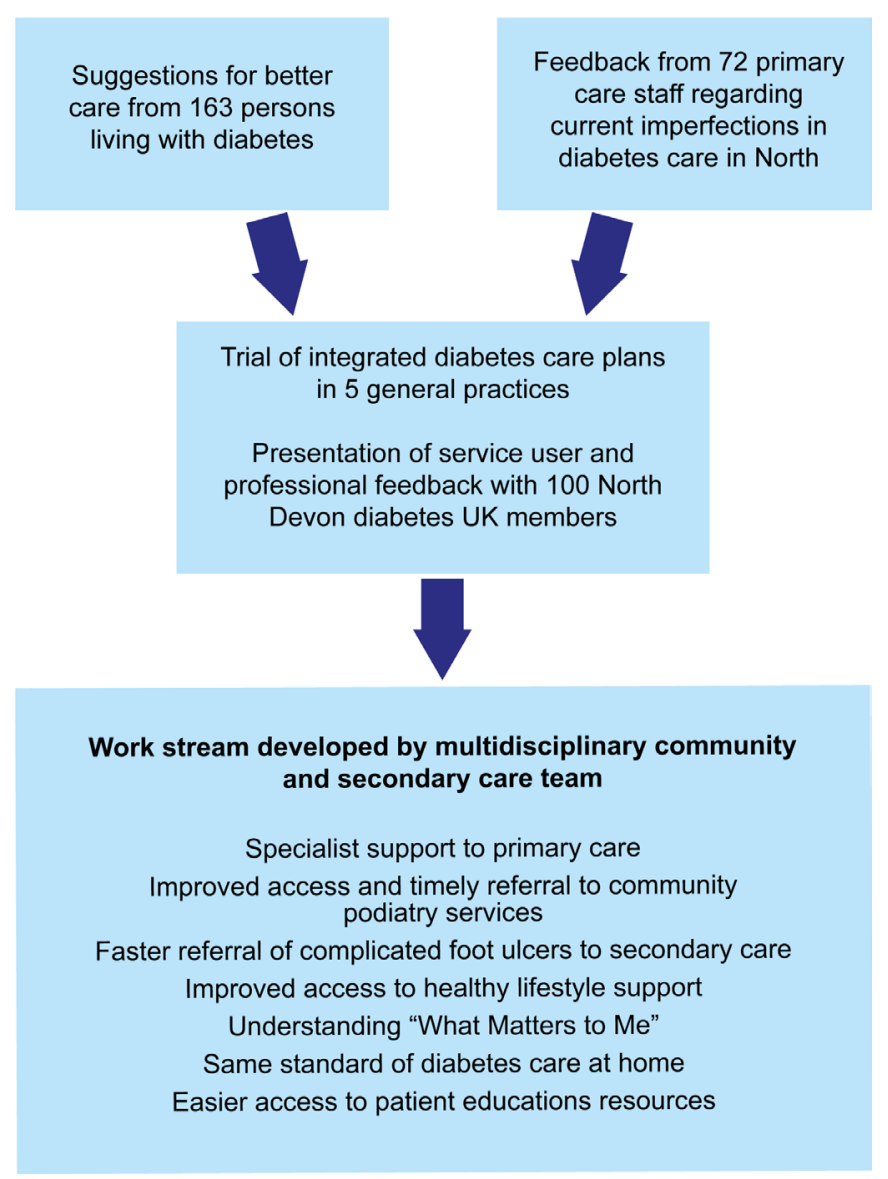

Figure 1 Flow chart outlining development of integrated diabetes care in North Devon.

\section{PARTICIPANTS AND METHODS}

The flow chart figure 1 shows the outline of information gathered from service users and community clinicians that provided the framework for development of the integrated care work streams. Details of the engagement with respondents and care improvements were presented to the clinical commissioning group (CCG) in early 2018 (online supplemental documents 1 and 2). Questionnaire responses and focus group transcriptions from service users and community staff are available from North Devon District Health Foundation Trust.

\section{Service user (persons living with diabetes) engagement}

Issues felt by people with diabetes to be most relevant to them were gathered by a patient focus group of eight participants and 22 individual in-depth interviews. The main themes of their responses were incorporated into a questionnaire, which was disseminated by the North Devon Diabetes UK patient support group; invitation from general practice staff; and the secondary care diabetes team. Written consent was obtained. Two further patient focus groups (number 7-8 in each) were held to discuss the best ways of implementing some of the insights that were highlighted from responses to the questionnaire. A progress report was made to 100 members of the North Devon Diabetes UK group after 4 months to refine the implementation of the integrated care plan. 


\section{Clinical engagement}

Clinicians were engaged through general practitioner (GP) questionnaires, three GP forums and four primary care workshops attended by 72 diabetes trained healthcare professionals from 13 GP practices.

\section{Program development}

During 2017, the program management team initially led by the consultant diabetes lead AlW also included a service user, a lead podiatrist, a specialist nurse, a CCG representative, a general practitioner (GP), a pharmacist, a Diabetes UK representative, and a project manager. Four diabetes services were retained in secondary care in North Devon District Hospital: antenatal diabetes; the multidisciplinary diabetic foot clinic; insulin pump delivery; and the type 1 diabetes education course (Barnstaple Area Re-education, Nutrition \& Insulin (BARNI), Quismet approved and based on the Dose Adjustment For Normal Eating (DAFNE) program). The need expressed by service users for more locally based diabetes care and prompt access to education and dietary advice was integrated with community professional's aspirations to propose work streams.

\section{Development of work streams}

Seven work streams (interventions) were developed to address the feedback from engagement and delivered in 2018 and 2019:

1. Specialist support to primary care based on virtual clinics.

2. Improved access and timely referral to community podiatry services.

3. Provision of a weekly virtual multidisciplinary foot (MDFT) clinic led by the vascular surgeon.

4. Improved access to healthy lifestyle support.

5. Understanding patient needs through the 'What Matters to You' program. ${ }^{22}$

6. Same standard of diabetes care for hard-to-reach patients.

7. Easier access to patient education resources.

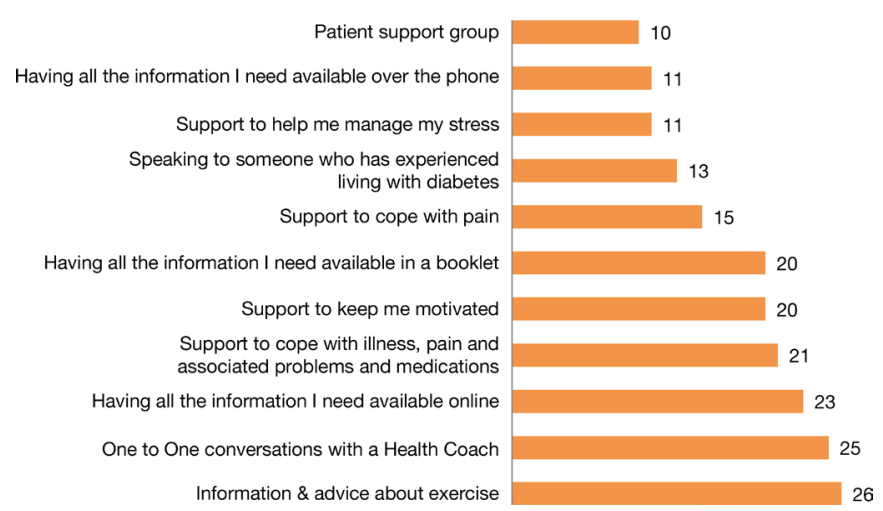

Figure 2 Summative analysis of 163 responses to questionnaire about diabetes services.

\section{Statistical analysis}

Significances of change from baseline to 6 months in weight and $\mathrm{HbAlc}$ after structured education were investigated with paired Student's t-tests. The incidences of amputation for North Devon only (part of Devon CCG) were analysed for patients residing in North Devon and compared with PHE diabetic foot care outcomes ${ }^{23}$ from 2012 to 2019. Details of the amputation data and analysis of outcomes after diabetes structured education are shown in online supplemental document 3. Bed occupancy in North Devon District Hospital was assessed by analysis as decomposition of time series to show trend of percentage bed occupancy (shown in online supplemental figures 1-3). Significance is expressed as linear regression.

\section{RESULTS}

\section{Initial scoping phase}

One hundred and sixty-three people living with diabetes responded to the questionnaire. The summative responses are shown in figure 2 .

Service users reported that Diabetes Specialist Education (DSE) group sessions in centers away from their locality were inconvenient and too time consuming to attend. Consistent themes expressed by service users indicated enthusiastic support for diabetes care to be delivered by practice staff and specialists in their own locality, but a recognition that the quality of existing primary care diabetes support in the locality varied. General practice staff felt that they should be reskilled to take over more complex diabetes-related problems. They highlighted that more effective pathways for referral for non-face-to-face advice would avoid unnecessary hospital appointments. There was also a wish to demedicalize type 2 diabetes treatments and focus on wider lifestyle issues. Comments most commonly expressed by general practitioners about the provision for diabetes care in North Devon before the integrated care programs are shown in the online supplemental table 1 . The need expressed by service users for more locally based diabetes care and prompt access to education and dietary advice was integrated with community professional's aspirations to propose work streams.

Problems encountered, interventions and outcomes of integrated diabetes care are shown in table 1.

Table 2 shows in detail the clinical outcomes of diabetic case reviews in multidisciplinary secondary care visits to primary care 2018-2019.

\section{Intervention 1: specialist support to primary care based on virtual} clinics

Virtual reviews of cases in general practice were initiated. Practice nurses and GPs presented individual histories of persons living with diabetes with diagnostic or treatment challenges. These case discussions were documented by the practice and progress followed up at subsequent annual review. 


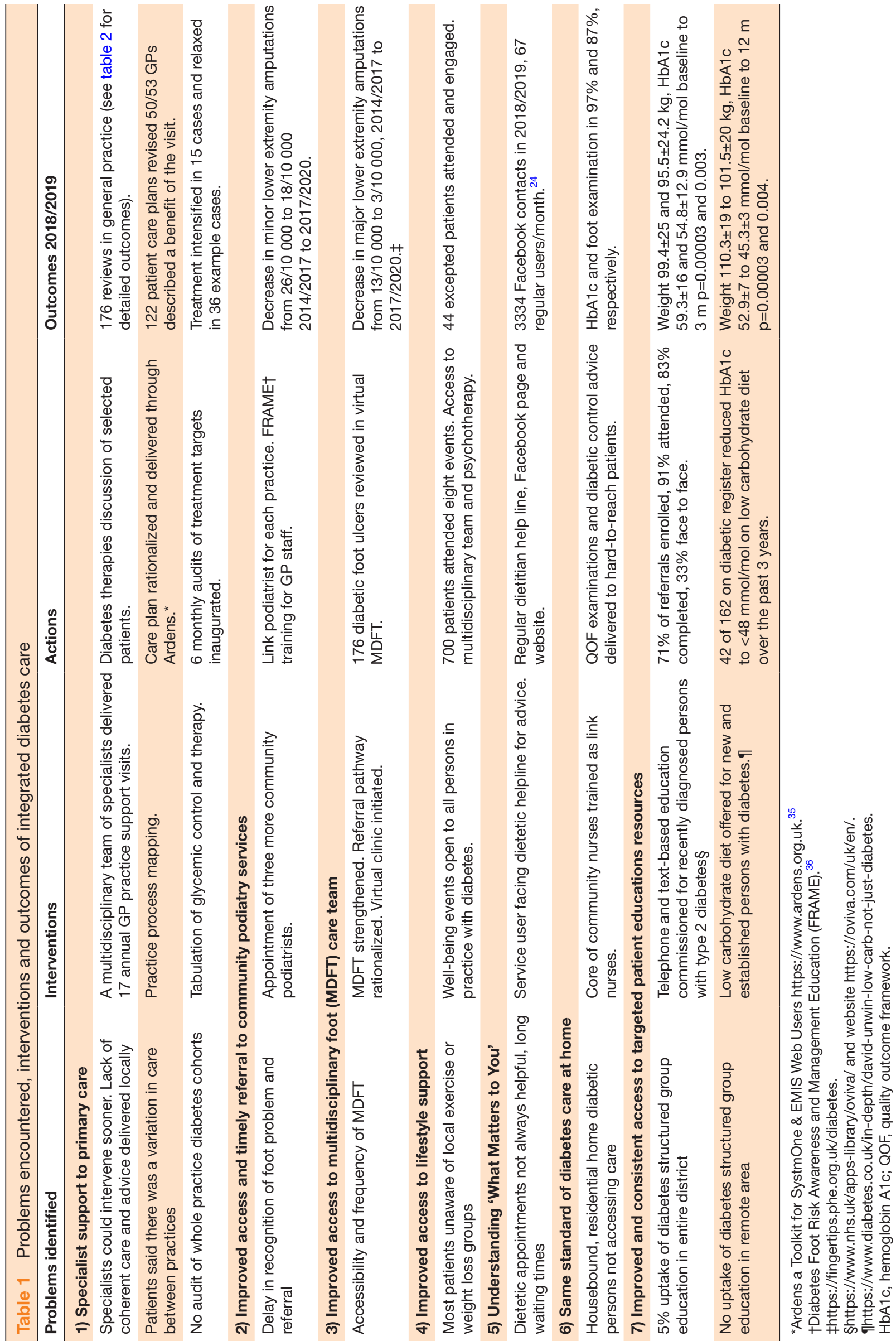




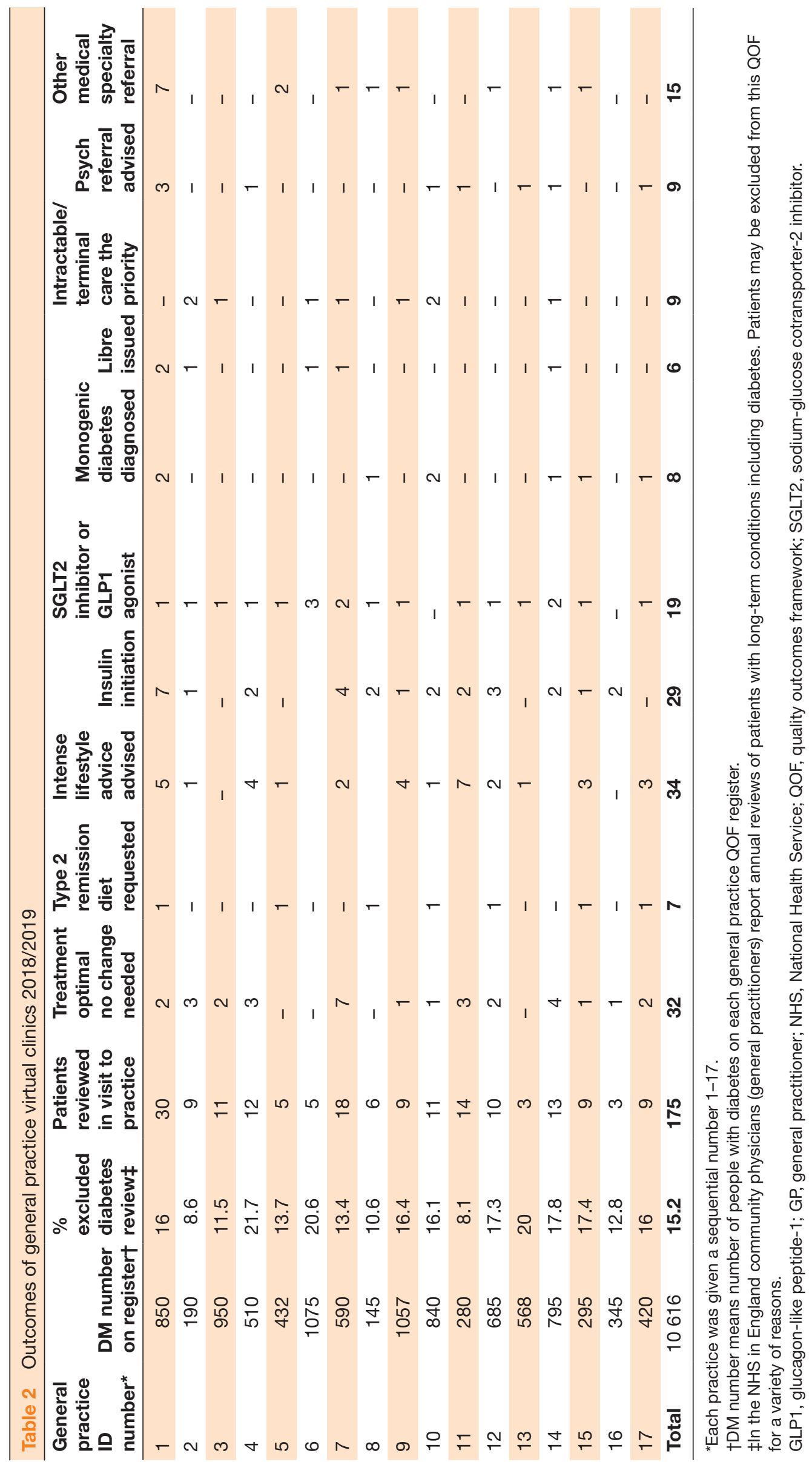


- One hundred and forty-one staff attended practice reviews in in 2018 and 2019, and 175 cases were reviewed.

- Only 24 (17\%) reviews resulted in referral to hospital specialists, 9 to psychiatry and 15 to nondiabetes specialists.

Tabulation of HbA1c levels in bands was stratified by therapy. The numbers of cases with low HbAlc $(<48$ $\mathrm{mmol} / \mathrm{mol})$, sum-optimal control of HbAlc $(>53<75$ $\mathrm{mmol} / \mathrm{mol})$ and poor control $(>75 \mathrm{mmol} / \mathrm{mol})$ were highlighted. Fifty-one selected cases in total were investigated to evaluate overtreatment of 36 frail persons and options for intensification of therapy in 15.

\section{Interventions 2: improved access and timely referral to community} podiatry services

Podiatry links with general practice were working well in 15 of 17 practices. In two practices, joint care had remained disjointed leading to delayed referrals of two severe diabetic foot problems. This was reviewed at the practice visit and addressed.

- Minor amputation incidence decreased from 26/10 000 before the integrated care program (greater than the upper CI for NHS England) to 18/10 000 for 3 years following it (less than the lower CI for NHS England). See online supplemental document 3.

- There is insufficient data to confirm that foot problems were referred more promptly to community podiatry.

\section{Intervention 3: provision of a weekly virtual MDFT clinic led by the}

\section{vascular surgeon}

The virtual MDFT was undertaken by the whole MDFT team led by the vascular surgeon and lead podiatrist for $90 \mathrm{~min}$ before the face-to-face clinic. An e-referral form was developed with facility to attach a dedicated mobile phone photograph of the foot ulcer. See online supplemental table 2. Community podiatrists, practice and community nurses could access the service. Service users were also enabled to send in foot ulcer photographs following intervention and discharge home.

In the first 2 years of the service, 416 virtual consultations of 220 individuals with foot ulcers were processed. Sixty eight per cent were male, mean HbAlc was $63 \pm 22.4$ $\mathrm{mmol} / \mathrm{mol}$, and mean age was $74.6 \pm 13.3$ years.

- Fifty per cent did not require face-to-face MDFT review.

- Fourteen per cent were admitted directly to the arterial center.

- Thirty six per cent were referred to the face-to-face 'one stop' MDFT clinic with preliminary blood tests, wound swabs, X-rays and in $14 \%$ duplex scans on the day of appointment.

- Major amputation incidence declined from a range of 13-15/10 000 annually for the 9 years before the integrated care program (greater than the upper CI for NHS England) to 3/10 000 afterwards from 2017 to 2020 (less than the lower CI for NHS England). See online supplemental document 3 .

Intervention 4: improved access to healthy lifestyle support

Twelve practices invited registered diabetic persons to eight separate locality-based well-being events. Each practice sent invitations to all persons identified with diabetes on the practice register. Seven hundred persons living with diabetes attended during 2018 and 2019.

- Lifestyle advice, cognitive-behavioral therapy appointments, foot examination and discussion of therapy were available at these events for persons living with diabetes.

- Service user feedback after these events is shown in online supplemental figure 4).

- Forty-four of 700 attending well-being events had not engaged in diabetic care for two or more years.

\section{Intervention 5: understanding patient needs through the 'What Matters to You' program}

A dietetic helpline and Facebook page were established to facilitate non-face-to-face in depth lifestyle discussions (What Matters to You), ${ }^{22}$ without the need for hospital referral.

- In the first 2 years, 3334 visits have been made to the Facebook page, ${ }^{24}$ which has included an 'eat well Wednesday' blog.

- Practice nurses have accessed this during diabetic consultations.

- The North Devon Health Diabetes website has been accessed more than 1000 times per month. ${ }^{25}$

The reasons for self-referral to the dietetic helpline are shown in figure 3 .

Intervention 6: same standard of diabetes care for hard-to-reach patients

Community nurses were invited to attend training courses in diabetes care run by a diabetic specialist nurse, podiatrist and dietitian with particular focus on insulin

Primary recorded reason for patients contacting the helpline

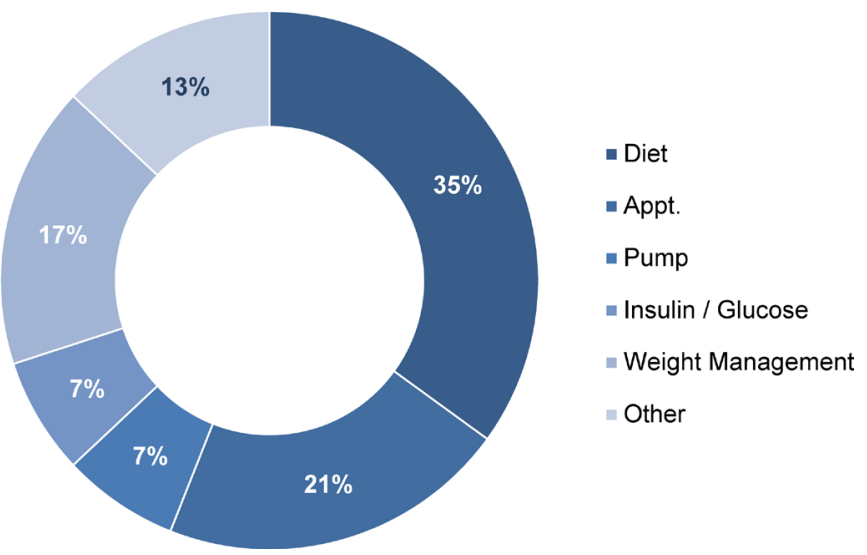

Figure 3 Reasons for accessing diet help line referral. 
adjustment, prevention of hypoglycemia, foot examination and collection of QOF data.

- Twenty-nine link community nurses have been trained to coordinate diabetes care for housebound and residential home persons with diabetes.

- Review of all long-term conditions and collection of QOF data was performed at home review for 41 service users in the first year: 2019.

\section{Intervention 7: easier access to patient education resources}

An NHS-approved telephone and text-based personalized education support for those recently diagnosed with diabetes has been in place for 2 years. The system Oviva ${ }^{26}$ is offered up to 2 years after diagnosis of type 2 diabetes and can be modified to include face-to-face, individual or group sessions at the service user's request. A full description of the program is shown in online supplemental document 4.

- Referral for DSE has increased from 5\% to 71\% (age range $40-84$ years), and $90 \%$ of those referred who engaged with the course completed the first year.

- Basic diabetes education, retinal screening and foot care were all included.

- Analysis of weight and HbAlc levels in the first 47 participants with new onset type 2 diabetes ( 18 female, age $61.3 \pm 13.7$ years) at baseline and 6 months were $99.4 \pm 25$ and $95.5 \pm 24.2 \mathrm{~kg}$ and $59.3 \pm 16$ and $54.8 \pm 12.9$ $\mathrm{mmol} / \mathrm{mol}$, respectively, $\mathrm{p}$ values 0.00003 and 0.003 .

- Improvement in $\mathrm{HbAlc}$ was significantly associated with weight loss: $\mathrm{R}^{2}=0.414, \mathrm{p}=0.001$.

- Eight of the cohort (two female, mean age 58.8 \pm 13.3 ) presented with HbA1c levels $>70 \mathrm{mmol} / \mathrm{mol}$. Weight loss and improvement in glycemia were satisfactory 3 months after starting the program: $102.4 \pm 27.4$ to $94.3 \pm 24.8 \mathrm{~kg}$, and $86.5 \pm 20.4$ to $69.0 \pm 17.4 \mathrm{mmol} / \mathrm{mol}$, $\mathrm{p}$ values 0.03 and 0.009 , respectively. These results have been sustained at 6 months.

\section{Single practice intervention}

In one general practice, low carbohydrate dietary advice based on the Unwin diet was offered to all those with new type 2 diabetes. ${ }^{27} 28$ This approach has been reported with similar results in another center. ${ }^{29}$

- Eight who engaged with the Unwin diet experienced a reduction in weight from $110.2 \pm 19$ to $101.5 \pm 20 \mathrm{~kg}$ and of HbAlc from $52.8 \pm 7$ to $45.2 \pm 3.4 \mathrm{mmol} / \mathrm{mol}$, at 1 year, $\mathrm{p}=0.00003$ for both weight loss and reduction in $\mathrm{HbAlc}$.

\section{Effect on bed occupancy for persons with diabetes}

Percentage of bed day occupancy by persons with diabetes through time shows a significant decrease between 2016 and 2020, regression $\mathrm{p}$ value of 0.03 see online supplemental figures 1-3.

\section{DISCUSSION}

The Northern Devon Healthcare Trust (NDHT) integrated diabetes care project was developed from 2017 after detailed discussions with service users in the area. Multidisciplinary virtual practice visits rationalized the diagnostic process for newly diagnosed diabetes, inaugurated audit of general practice diabetes lists (based on banding of HbAlc and therapy) and explored options for patients with significant diagnostic or management challenges. Link podiatrists and the virtual MDFT have been associated with sustained fall in major and minor diabetes related lower extremity amputations. North Devon health district had sustained very high diabetesrelated lower extremity amputation incidence for the previous 9 years despite peer reviews and an improvement in most of the rest of the southwest region. ${ }^{30}$ The decrease from 2017 to 2020 occurred after a peer review in 2015 followed by introduction of the integrated care service in 2017. STP funding enabled rapid introduction of significant improvements in diabetic foot care at all stages of the process: primary care, community podiatry, the face-to-face MDFT and a new virtual MDFT. Well-being events and diabetes training of a core team of community nurses have begun the process of engaging hard-to-reach persons living with diabetes. The community-facing website has sustained popularity. The Facebook page has facilitated direct contact between dietitians and persons living with diabetes and allowed healthcare professionals to access advice during consultations. A new telephone and text messaging-based approach to education of newly diagnosed persons with type 2 diabetes has increased engagement from $5 \%$ to $71 \%$. Improvement in weight and glycemic control was achieved, most markedly in those with highest weight and HbAlc at diagnosis. Persons living with diabetes in one very remote general practice area have enjoyed successful local intervention with a low carbohydrate diet. This affords another choice for those with newly diagnosed and established type 2 diabetes with minimum face-to-face contact. The decrease in bed occupancy by persons with diabetes in the district general hospital cannot be attributed with certainty to any one of the specific interventions introduced in the integrated care service. However, it is reassuring that a partially virtual service has been delivered in association with a reduction in percentage hospital bed occupancy for diabetes and improved outcomes for service users.

Approaches to diabetes care delivery in the community have been successful in several areas of the UK. Sustained success has been widely reported. ${ }^{10} 113132$ The rural nature of North Devon is most similar to West Hampshire where community-based diabetes integrated care has most effectively evolved over 5 years. ${ }^{18}$ This study is the first to achieve such a dramatic reduction in diabetesrelated lower extremity amputation incidence with integrated and partly virtual services.

The strength of this initiative derives from the keen participation of a selected group of persons living with diabetes in an entire health district (service users) and their acceptance of virtual clinics and mobile phone and text message-based learning. Engagement of those with diabetes through well-being events enabled 700 to meet 
the multidisciplinary care team in their own locality. This enabled 44 lost to follow-up to re-engage with diabetes care. With the advent of the COVID-19 pandemic, there is a need to explore virtual presentations to smaller groups of service users while maintaining social distancing. ${ }^{33} 34$

There are several limitations to this study. Primary care professionals, especially pharmacists and practice nurses, agreed with the need to have 'what matters to you' conversations. However, no extra time was allotted to have those conversations; therefore, follow-up of issues raised by service users was limited. In addition, the lack of electronic patient records for community nurses and podiatry made it difficult to make a detailed analysis of numbers and profiles of service users whose care was managed by the community link nurses in care homes and their own homes. Proof of reduction in late diabetic foot ulcer referral will require more detailed analysis over a longer time. More than $95 \%$ of the population served by North Devon District NHS Trust are white British living in semirural communities. However, there is every reason for city dwellers and all ethnic groups to be offered integrated diabetes care. NDHT is a geographically large health district, with a relatively small stable population (166 000) served by 17 general practices. Detailed liaison with general practice and community nurses was accomplished by a small team from secondary care. Several teams may be required in health districts with much larger populations. Multidisciplinary secondary diabetes care team visits to individual practices could be undertaken with web-based discussions at least until the COVID-19 epidemic has subsided. Areas where entirely virtual consultation will not be appropriate for diabetes care include annual review, retinal screening, antenatal diabetes care, initiation of insulin pumps, severe diabetic foot disease and end-stage renal failure therapy. Provision of diabetes care partly through virtual or nonface-to-face clinics demanded by the COVID-19 virus pandemic requires careful audit. This report is encouraging in that it describes the success of a partly virtual diabetes service developed during the 3 years before the pandemic. The improvements in outcomes and service user access support current initiatives to develop virtual diabetes clinical services more widely both during and after the COVID-19 pandemic.

\section{Author affiliations \\ ${ }^{1}$ Integrated Diabetes Care, Northern Devon Healthcare NHS Trust, Barnstaple, UK ${ }^{2}$ Department of Integrated Care, Northern Devon Healthcare NHS Trust, Barnstaple, UK \\ ${ }^{3}$ Integrated Diabetes Care, Bideford Medical Centre, North Devon, Barnstaple, UK}

Acknowledgements We wish to pay tribute to AIW who planned and initiated the integrated diabetes care program in North Devon and was actively involved until his untimely death.

Contributors JW, RB, LW and KD developed and delivered the virtual multidisciplinary foot (MDFT). EW, AmW and LP-M developed and delivered the website, Facebook page and dietetic non-face-to-face service. EB, GR, PB, RP and $A B$ developed and delivered the general practice care plan discussions and virtual general practice clinics. All living authors gave final approval and agreed to be accountable for all aspects of work ensuring integrity and accuracy. AIW designed and initiated the project development. General practice staff have engaged enthusiastically in all aspects of the integrated diabetes care program. Glen Allway, Karen Acott (practice leads), Matt Robert (DUK South West), Mel Hucker (tissue viability service), Pat Doran (service user), Sharon Bates (practice manager and CCG adviser), John Wilkins and Hannah Keigthley (project support managers) contributed to monitoring of the integrated diabetes care development program. Toni Pascoe-Knight provided diabetes specialist nurse support to the MDFT. The Barnstaple branch of Diabetes UK contributed to wellbeing events, service user recruitment for focus groups and participation in questionnaires. Thanks to Melvin Cowie for graphic design and Rosamund Paisey for formatting the manuscript. Nicolas Harrison, principal analyst, North Devon Healthcare, provided data analysis of bed occupancy and education program follow up. Ruth Tapsell initiated and followed up low carbohydrate diet therapy at Hartland general practice, Devon, UK. Statistical advice was provided by Dr Paul Hewson and Dr Christopher Paisey.

Funding Funding was received from the Sustainability and Transformation Programme in 2017

Competing interests None declared.

Patient consent for publication Not required.

Provenance and peer review Not commissioned; externally peer reviewed.

Data availability statement All data relevant to the study are included in the article or uploaded as supplemental information.

Supplemental material This content has been supplied by the author(s). It has not been vetted by BMJ Publishing Group Limited (BMJ) and may not have been peer-reviewed. Any opinions or recommendations discussed are solely those of the author(s) and are not endorsed by BMJ. BMJ disclaims all liability and responsibility arising from any reliance placed on the content. Where the content includes any translated material, BMJ does not warrant the accuracy and reliability of the translations (including but not limited to local regulations, clinical guidelines, terminology, drug names and drug dosages), and is not responsible for any error and/or omissions arising from translation and adaptation or otherwise.

Open access This is an open access article distributed in accordance with the Creative Commons Attribution Non Commercial (CC BY-NC 4.0) license, which permits others to distribute, remix, adapt, build upon this work non-commercially, and license their derivative works on different terms, provided the original work is properly cited, appropriate credit is given, any changes made indicated, and the use is non-commercial. See: http://creativecommons.org/licenses/by-nc/4.0/.

ORCID iD

Richard Paisey http://orcid.org/0000-0002-7790-2569

\section{REFERENCES}

$1 \operatorname{Hex} \mathrm{N}$, Bartlett C, Wright D, et al. Estimating the current and future costs of type 1 and type 2 diabetes in the UK, including direct health costs and indirect societal and productivity costs. Diabet Med 2012;29:855-62.

2 Public health profiles, 2019. Available: https://fingertips.phe.org.uk/ profile/diabetes-ft [Accessed 9 Sep 2019].

3 NHS Digital. National diabetes audit programme. Available: https:// digital.nhs.uk/data-and-information/clinical-audits-and-registries/ national-diabetes-audit [Accessed 25 Nov 2019].

4 NHS Digital. National diabetes foot care audit, 2014-2018. NHS digital, 2019. Available: https://digital.nhs.uk/data-and-information/ publications/statistical/national-diabetes-footcare-audit/2014-2018 [Accessed 18 Jun 2019].

5 NICE. Foot care for people with diabetes overview - NICE Pathways, 2019. Available: https://pathways.nice.org.uk/pathways/foot [Accessed 18 Jun 2019].

6 Jeffcoate WJ, Vig S, Swage T. NHS Diabetes commissioning documents \& guidance - Diabetes UK, 2011. Available: http://www. diabetes.nhs.uk/commissioning_resource/ [Accessed 29 Nov 2016].

7 Stratton IM, Adler Al, Neil HA, et al. Association of glycaemia with macrovascular and microvascular complications of type 2 diabetes (UKPDS 35): prospective observational study. BMJ 2000;321:405-12.

8 Colhoun HM, Betteridge DJ, Durrington PN, et al. Primary prevention of cardiovascular disease with atorvastatin in type 2 diabetes in the Collaborative atorvastatin diabetes study (cards): multicentre randomised placebo-controlled trial. Lancet 2004:364:685-96.

9 NHS Digital. Quality and Outcomes Framework, Achievement, prevalence and exceptions data - 2017-18 [PAS], 2018. Available: https://digital.nhs.uk/data-and-information/publications/statistical/ 
quality-and-outcomes-framework-achievement-prevalence-andexceptions-data/2017-18 [Accessed 28 Jun 2019].

10 Rea RD, Gregory S, Browne M, et al. Integrated diabetes care in Derby: new NHS organisations for new NHS challenges. Practical Diabetes 2011;28:312-3.

11 Diabetes UK. Improving the delivery of adult diabetes care through integration, 2014. Available: https://www.diabetes.org.uk/resourcess3/2017-11/integrated\%20diabetes\%20care $\% 20 \% 28$ pdf $\% 2$ C\% 20648kb\%29.pdf [Accessed 3 Dec 2020].

12 Integrated GP led diabetes care in Bexley. The role of 'an active integrator' in developing integration in NHS services, 2012. Available: www.bexley.diabetesukgroup.org

13 Schwingshackl L, Dias S, Hoffmann G. Impact of long-term lifestyle programmes on weight loss and cardiovascular risk factors in overweight/obese participants: a systematic review and network meta-analysis. Syst Rev 2014;3:130.

14 Alharbi M, Gallagher R, Kirkness A, et al. Long-Term outcomes from healthy eating and exercise lifestyle program for overweight people with heart disease and diabetes. Eur J Cardiovasc Nurs 2016;15:91-9.

15 Hayes TM, Harries J. Randomised controlled trial of routine hospital clinic care versus routine general practice care for type II diabetics. Br Med J 1984;289:728-30.

16 Kar P. The 'super six' for the acute trust; all else under primary care? Practical Diabetes 2011;28:308-9.

17 Introducing personalised care planning into Newham: outcomes of a pilot project.

18 Successful recommissioning of community diabetes services in West Hampshire.

19 Gottlieb K. The Nuka system of care: improving health through ownership and relationships. Int J Circumpolar Health 2013;72:72.

20 Public health profiles. Available: https://fingertips.phe.org.uk/ profile/tobacco-control/data\#page/1/gid/1938132885/pat/6/par/ E12000009/ati/102/are/E06000027 [Accessed 2 Mar 2019].

21 NHS England. Diabetes transformation fund. Available: https:// www.england.nhs.uk/diabetes/diabetes-prevention/diabetestransformation-fund/ [Accessed 6 Jun 2020].

22 NHS England. What matters to you. Available: https://www.england. nhs.uk/what-matters-to-you/ [Accessed 3 Jun 2020].

23 Diabetes Footcare - PHE. Available: https://fingertips.phe.org.uk/ profile/diabetes-footcare [Accessed 6 Nov 2020].
24 North Devon integrated diabetes service. Available: https://www. facebook.com/NorthDevonIntegratedDiabetesService/ [Accessed 3 Jun 2020].

25 North Devon Health care Trust. North Devon diabetes website. Available: https://www.northdevonhealth.nhs.uk/services/diabetes/ diabetes-healthcare-professional/dietitians/

26 Diabetes support. Oviva. Available: https://oviva.com/uk/en/ diabetes-support/ [Accessed 7 Jun 2020].

27 Unwin D, Unwin J. Low carbohydrate diet to achieve weight loss and improve $\mathrm{HbA}_{1 \mathrm{c}}$ in type 2 diabetes and pre-diabetes: experience from one general practice: Low carbohydrate diet to achieve weight loss and improvements in $\mathrm{HbA}_{1}$. Practical Diabetes 2014;31:76-9.

28 Feinmann J. Hope for diabetes: five minutes with David Unwin. BMJ 2020;368:m404.

29 Ahmed SR, Bellamkonda S, Zilbermint M, et al. Effects of the low carbohydrate, high fat diet on glycemic control and body weight in patients with type 2 diabetes: experience from a community-based cohort. BMJ Open Diabetes Res Care 2020;8:e000980.

30 Paisey RB, Abbott A, Levenson R, et al. Diabetes-related major lower limb amputation incidence is strongly related to diabetic foot service provision and improves with enhancement of services: peer review of the South-West of England. Diabet Med 2018;35:53-62.

31 Pal K, Eastwood SV, Michie S, et al. Computer-based diabetes selfmanagement interventions for adults with type 2 diabetes mellitus. Cochrane Database Syst Rev 2013:CD008776.

32 Coulter A, Entwistle VA, Eccles A, et al. Personalised care planning for adults with chronic or long-term health conditions. Cochrane Database Syst Rev 2015:CD010523.

33 Gov.UK. Staying alert and safe (social distancing). GOV.UK coronavirus (COVID-19) guidance and support. Available: https:// www.gov.uk/government/publications/staying-alert-and-safe-socialdistancing/staying-alert-and-safe-social-distancing [Accessed 2 Jun 2020].

34 NHS.UK. Social distancing and changes to everyday life Coronavirus (COVID-19) - NHS. NHS Coronavirus (COVID-19). Available: https://www.nhs.uk/conditions/coronavirus-covid-19/ social-distancing/ [Accessed 2 Jun 2020].

35 Ardens The Complete Toolkit For SystmOne \& EMIS Web Users. Available: https://www.ardens.org.uk/ [Accessed 10 Nov 2020].

36 Frame | diabetes foot screening home. Available: http://www. diabetesframe.org/ [Accessed 20 Feb 2017]. 